\title{
La representación de la crisis española en la publicidad. El caso de Despertar (Campofrío, 2015)
}

\author{
Samuel Gil Soldevilla'; Elvira Antón-Carrillo ${ }^{2}$
}

Recibido: 18 de diciembre de 2017 / Aceptado: 1 de marzo de 2018

Resumen. Este artículo presta atención a la enunciación publicitaria entendiéndola como un discurso que construye una imagen, entre las muchas posibles, de la crisis. Teniendo en cuenta que las grandes empresas prefieren apelar a nuestro optimismo antes que contribuir a un debate racional sobre nuestras problemáticas, y que desde su naturaleza persuasiva su objetivo no es solucionar nuestros problemas cotidianos o empoderarnos con capacidades críticas sino fomentar el consumismo, llevamos a cabo un análisis crítico del discurso multimodal y semiótico de la publicidad, sus estrategias discursivas, así como sus objetivos e intereses. Centrándonos en el caso español, analizaremos a modo de estudio de caso paradigmático la campaña Despertar de Campofrío (2015). Veremos cómo la representación de la crisis en el spot resta importancia a la misma al des-socializarla y des-politizarla, a la vez que la individualiza, así como sus posibles causas, consecuencias y soluciones, apoyando y legitimando la ideología neoliberal presente en la sociedad. La marca se ofrece así como terapeuta, coach personal e incluso gurú espiritual para superar una crisis expresada como oportunidad.

Palabras clave: Publicidad; crisis económica; análisis semiótico; análisis crítico del discurso multimodal; espiritualidad.

\section{[en] Representation of Spanish Crisis in Advertising. The Case of Awakening (Campofrío, 2015)}

\begin{abstract}
This paper pays attention to the advertising enunciation, understanding it as a discourse that builds an image, among many possible, of the crisis. Taking into account that large companies prefer to appeal to our optimism rather than contribute to a rational debate about our problems, and that from its persuasive nature its objective is not to solve our daily problems or to empower us with critical capacities but to promote consumerism, we carry out a critical analysis of the multimodal and semiotic discourse of advertising, its discursive strategies, as well as its objectives and interests. Focusing on the Spanish case, we will analyse Campofrio's Despertar campaign (2015) as case study. We will see how the representation of the crisis in the advertisement takes away the importance of the crisis because it does not take into account social and political issues. At the same time it individualizes it, as well as its possible causes, consequences and solutions, supporting and legitimizing the neoliberal ideology present in society. The brand is offered as well as therapist, personal coach and even spiritual guru to overcome a crisis expressed as opportunity.
\end{abstract}

Keywords: Advertising; Economic Crisis; Semiotic Analysis; Critical Analysis of Multimodal Discourse; Spirituality

1 Universidad Jaume I, Castellón (España)

E-mail: ssoldevi@uji.es

2 University of Roehampton, Londres (Reino Unido)

E-mail: e.anton@roehampton.ac.uk 
Sumario. 1. Introducción y antecedentes. 2. Aspectos metodológicos y selección del case study. 3. Análisis del spot: Despertar, Campofrío (2015). 4. Conclusión. 5. Bibliografía

Cómo citar: Gil Soldevilla, S. y Antón-Carrillo, E. (2017) La representación de la crisis española en la publicidad. El caso de Despertar (Campofrío, 2015), en Área Abierta. Revista de comunicación audiovisual publicitaria 18 (2), 293-308. http://dx.doi.org/10.5209/ARAB.57347

\section{Introducción y antecedentes}

La publicidad es el animador del consumo, la voz e imagen seductora del capitalismo. Hoy en día la propuesta consumista que se materializa a través del discurso publicitario es especialmente poderosa. Hemos de tener presente que la publicidad se crea para influir en las decisiones de su público y convencer, sugestionar y seducir; por lo tanto, la ideología que transmite no es sencillamente y omnipresentemente mostrada, sino que es incisivamente desplegada por toda una panoplia de profesionales, herramientas y tecnologías creativas, icónicas, audiovisuales, textuales y discursivas. Implícita o explícitamente, la publicidad nunca es ideológicamente imparcial sino que constituye una (re)creación de la realidad combinando la aparente representación del día a día con una alta dosis de ficción.

Nuestro objetivo en este texto es hacer un análisis crítico del discurso multimodal del spot publicitario Despertar de Campofrío España, campaña de Navidad 2015, con la intención de descubrir su representación de la crisis, cómo se la define e interpreta, así como las estrategias de discurso que están presentes en el spot, sus objetivos e intereses. Particularmente se pretende explicitar, mediante este caso paradigmático y desde una visión ahora madurada, la utilización de estrategias extensibles al conjunto de la práctica publicitaria española a partir de un discurso acrítico y de esencia emocional.

Según un artículo publicado en el periódico El Mundo (Planelles, 2009), basado en datos de Infoadex, más de un centenar de anuncios lanzados desde el 1 de enero de 2009 hasta el 13 de marzo de ese mismo año en prensa, radio, televisión y publicidad exterior contenían la palabra crisis ${ }^{3}$. Sin embargo, esos anuncios que incluyen la palabra crisis son solo una parte de las empresas que utilizan la situación económica como recurso creativo, aunque la intención de las marcas sea la de aportar un mensaje de optimismo e ilusión frente a la incertidumbre y la desconfianza. Es el caso de la campaña de Coca-Cola, de 2009 (principio de la crisis), en la que un anciano de 102 años le dice a un recién nacido que aunque llegue al mundo en un momento como éste: "Estás aquí para ser feliz". Según Mónica Moro, directora creativa de la agencia McCann y responsable del anuncio de la marca, en declaraciones recogidas en Planelles (2009): "Se trataba de hablar de la crisis de una forma distinta, de hacer algo más icónico, de crear una campaña que nos quitara un poco el derrotismo, el 'quejido colectivo' y dar el mensaje de que 'esto va a pasar' [...] la publicidad está asumiendo el papel de animador social".

3 "Basta ya de crisis" (Segunda Mano), "Con la crisis sí se juega" (Famosa), "Dale calabazas a la crisis" (Knorr), o "Desmárcate de la crisis" (Línea directa), son algunos ejemplos. 
En su artículo titulado "Las estrategias publicitarias de las marcas en el contexto de crisis", Fernández, Alameda \& Martín (2011) estudian las estrategias publicitarias que desarrollan los principales anunciantes del panorama nacional de diferentes sectores de consumo. Entre sus conclusiones se encuentran que se tiende a trabajar con valores de posicionamiento relacionados con la crisis y basados en lo intangible, con una línea emocional y de relación con el consumidor:

La comunicación está basada más en la emoción y en los sentimientos, busca la vinculación afectiva entre la marca y el consumidor, mediante contenidos dirigidos a sus sentidos (alegría, felicidad, posibilidades, anhelos, sueños). Las historias reales de la gente ganan terreno frente a los mensajes anodinos de productos (Fernández et al., 2011: 135).

Las conclusiones del estudio de Garrido Lora, Rey y Ramos-Serrano (2012) sobre el eslogan gráfico publicitario apuntan a una mayor concentración expresiva, mayor número de recursos retóricos y mayor protagonismo del consumidor en su concepto creativo, observando la incidencia que la crisis económica ha tenido en la publicidad en aspectos como la economía expresiva, la densidad semántica, la brillantez y uso de recursos retóricos, así como la perdurabilidad, la exclusividad o la eficiencia comunicativa.

Castelló, Ramos y Del Pino (2013) en su estudio sobre campañas de publicidad en televisión entre diciembre de 2012 y febrero de 2013 en España, demuestran que la coyuntura de la crisis afecta al sector publicitario, no solo en términos económicos, sino con profundos cambios en la publicidad convencional, los nuevos medios, el rol activo del espectador, las redes sociales, etc., y destacan el interés del discurso por narrar historias que afectan directamente al ciudadano, incidiendo en la importancia del binomio compromiso-valores. La publicidad apela así a mecanismos post materialistas, catalizando aspiraciones de la sociedad y fomentando el positivismo y la autorrealización.

Rodríguez Serrano, Gil Soldevilla y Marzal Felici (2015) trabajan la campaña de Branded Content Cinergía, generada para la compañía Gas Natural Fenosa en 2015. En su texto exponen la relación entre la marca, el habitar y la crisis económica. Los cuatro cortometrajes que componen la primera temporada de la propuesta Cinergía se hacen cargo del problema del habitar en el marco de la crisis económica mundial, utilizando al menos tres estrategias distintas: la crisis del habitar doméstico (mediante la mostración de espacios familiares o íntimos inhabitables), la crisis del habitar subjetivo en lo real (mediante la mostración de quiebras personales) y la crisis de la propia función artística, dominada pero no comprendida por actividades de patrocinio y mecenazgo que resultan, a la postre, incompatibles con el potencial emancipador y autónomo del texto artístico.

Un repaso de las principales investigaciones demuestra la pertinencia académica de profundizar en el fenómeno comunicativo publicitario en un contexto de crisis económica como la española. Tras esta revisión de los antecedentes empíricos, realizaremos nuestro análisis crítico del discurso multimodal que situaremos en el contexto sociológico actual, caracterizado por su propuesta de felicidad subjetiva, terapéutica y de cierto ánimo espiritual. 


\section{Aspectos metodológicos y selección del Case Study}

Para este análisis se ha seleccionado como objeto de estudio un ejemplo ilustrativo y de peso cualitativo de la relación entre crisis en España y discurso publicitario. En concreto se ha optado por la campaña Despertar (2015) de la marca Campofrío 4 , que cuenta con una trayectoria creativa reconocida, y que ha tratado el tema de la crisis de manera constante desde 2011. De hecho, la marca ha conseguido provocar entre los espectadores una especie de expectativa de sus campañas navideñas, las cuales son comentadas y compartidas en los medios de comunicación como un elemento casi tradicional de este periodo de final de año. Este eco mediático y social es paradigmático e indicador de su relevancia alcanzando en el canal de Youtube de la compañía los casi tres millones y medio de visualizaciones on-line.

La publicidad ofrece una versión o representación de la sociedad y lo que acontece, y el spot o anuncio publicitario, como producto audiovisual construye su significado a través de diferentes modos semióticos: imágenes, palabras, sonidos, etc., y lo transmite a través de símbolos. Una multimodalidad que definimos con Kress y Van Leeuwen (2001) como el uso de varios modos semióticos en el diseño de un evento o producto semiótico, así como la forma en la que estos modos se combinan, pueden reforzarse mutuamente, cumplir roles complementarios, o estar jerárquicamente ordenados. Definimos la comunicación como un proceso en el que un producto o evento semiótico es articulado, producido e interpretado y usado. Entendemos con Van Dijk (1999) que, para que el spot cumpla su propósito comunicativo, esos símbolos tienen que ser entendidos por el público que lo recibe, en este caso, por la sociedad española, a quien va dirigido. Por ello, los referentes deben ser socialmente compartidos, y reflejarán creencias y opiniones socialmente aceptadas, así como valores e ideologías vigentes. Entienden los estudios críticos del discurso que una cultura se expresa en sus recursos simbólicos, lo que implica que sintetiza no solo su historia sino el conjunto de saberes que se postulan en una sociedad.

Tendremos en cuenta también en nuestro análisis el concepto de contexto, formulado y desarrollado por Van Dijk (2008), como el conjunto de conocimientos que poseen los interlocutores para la producción y comprensión de su acto de comunicación. En el contexto, como constructo cognitivo, los interlocutores reconocen experiencias, percepciones, opiniones, conocimientos, puntos de vista y emociones, que se actualizan en la situación comunicativa y que le otorgan sentido. Estos conocimientos o saberes proceden de modelos de experiencia y en este sentido son subjetivos y se articulan con conocimientos comunes, actitudes e ideologías, y en esa medida son intersubjetivos. Éstos tienen la función de garantizar los grados

4 Campofrío Food Group, en la actualidad una empresa multinacional de alimentación, se creó en Burgos en 1952. En España opera por medio de la compañía Campofrío España, que aporta el $40 \%$ de facturación del grupo. Cuenta con seis plantas de producción distribuidas por toda la península y con más de 20 centros, y además, existen otras 7 empresas independientes en Europa dentro del grupo. Tanto la empresa, como sus propietarios han pasado por diversos cambios. Según la página web del grupo (Campofrío Food Group, s. f.), en 2004 la americana Smithfield Foods compró el 22\%, y la empresa se convierte en Campofrio Food Group. En 2013 la china Shuanghui, al comprar Smithfield Foods, se apropia de la participación estadounidense en Campofrío. En 2014, la compañía china comparte Campofrío con la mexicana Sigma, y, en junio de 2015 la mexicana Sigma compra su participación a la china Shuanghui convirtiéndose en la propietaria única de Campofrío. 
de adecuación requeridos para que los entornos cognitivos y socio-culturales se relacionen coherentemente en la interacción comunicativa. En consecuencia, el enfoque socio-cognitivo del análisis crítico del discurso hace énfasis en la explicación e interpretación que se deriva de las formas de cognición que se producen, distribuyen y comprenden.

En la filosofía publicitaria actual uno de los argumentos inmateriales más importantes, frente al concepto de crisis, es la consecución de la felicidad. La asociación consumo-felicidad se ha convertido en el sistema de referencia para el individuo contemporáneo sea cual sea su contexto. La novedad de nuestra época no está en que el individuo se preocupe por la búsqueda de la felicidad sino en que la moderna sociedad de consumidores se ha comprometido a brindar felicidad a través de los bienes materiales en el momento presente, no en una ensoñación o utopía futura. Como apunta Bauman, "la sociedad de consumidores es quizás la única en la historia humana que pretende felicidad en la vida terrenal, felicidad aquí y ahora y en todos los 'ahoras' siguientes, es decir, felicidad instantánea y perpetua" (Bauman, 2007: 73). La publicidad hace las cosas mejores, nos muestra el camino hacia una vida glorificada a través del consumo. No es parte del problema, sino que ofrece la solución ${ }^{5}$. Esta promesa de una vida feliz es un "metavalor" o valor supremo que justifica su valor y existencia (Bauman, 2010: 238). Las marcas se erigen entonces, sutilmente, como garantes y proveedoras de una felicidad democratizada, alcanzable e instantánea.

Despertar (2015) sigue la estrategia creativa de las campañas anteriores (20112014), alrededor del eslogan "que nadie nos quite nuestra manera de disfrutar de la vida", y soporta su posicionamiento en la idea de que a pesar de las dificultades provocadas por la crisis económica que está sufriendo España hay que "disfrutar de la vida", a "nuestra manera". El concepto creativo es el de trasladar una idea de positividad e inspirar ánimo a la sociedad. El objetivo publicitario de la campaña busca que se asocien a la marca Campofrío los valores que las sucesivas campañas pretenden comunicar: optimismo, ilusión y esperanza, generalmente a través del espíritu de superación y el sentido del humor, apelando a las emociones de los receptores. La campaña de 2015, Despertar, será la última alrededor de este eslogan y que se centra en el contexto de la crisis. En palabras de Mónica Moro, Directora General Creativa de McCann, "es una llamada de atención a todos para despertar a la vida, abrir los ojos y descubrir cosas fascinantes y tremendamente pequeñas que nos hacen disfrutar" (Campofrío Food Group, s.f.).

\section{Análisis del spot: Despertar, Campofrío (2015)}

Un hombre (Tristán Ulloa) de mediana edad despierta tras pasar mucho tiempo en coma. Con la guía de su mujer (Emma Suárez) va redescubriendo con ojos inocentes y curiosos a su hija, familiares, amigos, y también sus costumbres, lugares habituales

5 (Gottschalk, 2009) analiza cientos de formas superlativas en los eslóganes publicitarios evidenciando sus excesos de valor lingüísticos (en cuanto calidad, cantidad, espacio o tiempo) y demostrando la obsesión publicitaria por presentar un mundo solucionado a través del consumo de sus productos, servicios o ideas. Una retórica megalómana que contribuye al proyecto totalizador consumista. 
y sentimientos. En el spot aparecen reflejados algunos aspectos socioculturales normalmente asociados con España (fútbol en el bar, siesta, humor, fiesta, el pueblo, la comida, celebraciones), hasta que un amigo del protagonista, que lee un periódico, se queja de la actual situación que se vive en España. Pero el protagonista, desde su experiencia tras el coma y tras haber redescubierto el mundo, le asegura que hay demasiadas cosas cada día por las que merece la pena abrir los ojos, levantarse y salir a vivir. El producto aparece de forma marginal y el spot se cierra con el eslogan: "Que nadie nos quite nuestra manera de disfrutar de la vida" y el pack shot del logotipo de Campofrío como firma.

La campaña Despertar muestra varios cambios respecto a las anteriores en los diferentes estratos de la creación del anuncio. En el estrato denominado diseño o concepto creativo, mientras que todas las campañas anteriores se hacen en clave de humor (aunque no están organizados como una historia) y pertenecen al género comedia, Despertar tiene un diseño y lenguaje de corto cinematográfico y una estructura perteneciente al género dramático que relata una historia de vida. En las anteriores campañas el protagonista es un colectivo, de cómicos, de emigrantes, de ciudadanos, de famosos, de todos los españoles; en general es un nosotros nacional, representado por los famosos y homogeneizado por nuestra manera de disfrutar de la vida. En el caso de Despertar el protagonista no es un colectivo, sino un individuo. La propuesta, y la responsabilidad de la resolución de la crisis pasa a ser individual $\mathrm{y}$, en vez de prestar atención a las grandes cosas, como en el Curriculum de todos, lleno de grandes logros y hazañas, se proponen las cosas pequeñas y cotidianas como solución a la crisis para lograr la felicidad. El cambio más importante en el discurso se da en el hecho de que en vez de situar la acción en el contexto de la crisis, representada en los anteriores spots a través de sus consecuencias sociales — desánimo, depresión, falta de autoestima, emigración, cierre de negocios_-, en Despertar se representa desde una de las consecuencias psicológicas en el individuo, como trauma, y la solución terapéutica a nivel individual que permita superar el estado de crisis.

\subsection{Planteamiento dramático: crisis como enfermedad}

La crisis se representa como una enfermedad, un estado de coma del que el protagonista sale, despierta a la realidad, como ya sugieren el título del spot y el planteamiento dramático de éste. En las primeras imágenes el protagonista, en una habitación de hospital en la que ha estado en coma durante mucho tiempo, y cuando ya no se esperaba, vuelve a la vida, aunque ha perdido la memoria. El paciente, representado por el actor Tristán Ulloa, muy conocido por su papel protagonista en la serie de La 1 de televisión española Gran Reserva (2010-2013), en el primer capítulo de la serie, pasa por una situación idéntica: ha sufrido un traumatismo cráneo encefálico que lo tiene en el hospital, en coma, y al salir del coma ha perdido la memoria. En ambos casos sirve como planteamiento dramático de la historia que se va a contar. 

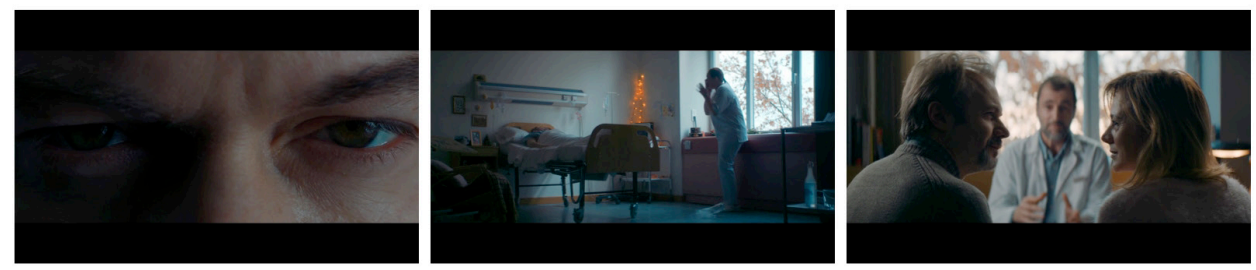

Figura 1. Planos 4, 8 y 13 del spot Despertar de Campofrío (2015).

[Fuente: spot Despertar de Campofrío (2015)]

La intertextualidad, recurso retórico y discursivo, es definida por De Beaugrande y Dressler (1981) como la relación de dependencia que se establece entre los procesos de producción y recepción de un texto, así como al conocimiento que tengan los participantes en la comunicación de otros textos o discursos relacionados con el que está teniendo lugar. Se activaría con la intertextualidad un proceso de mediación en la que la subjetividad del participante en la comunicación introduce sus propias creencias en el modelo mental de la situación en curso (De Beaugrande y Dessler, 1981). Esta intertextualidad constituiría lo que Van Dijk (1999) denomina modelo mental, una representación subjetiva de acontecimientos específicos, a través de los cuales interpretamos eventos o textos. Es decir, para aquellas personas que vieron la serie Gran Reserva ${ }^{6}$ esta intertextualidad constituiría un modelo de acontecimiento del que tienen una representación mental. Pone al espectador de parte del protagonista pues le es familiar, y le prepara para el desarrollo de la transformación que tendrá lugar en él, a la manera que ocurre en el protagonista de la serie Gran Reserva, quien pasa de ser un hombre manipulador y egoísta (para quien lo único que importa son los valores materiales de su empresa y conseguir el éxito), a convertirse en un hombre nuevo, noble y solidario.

Este despertar transformador sigue también el de otros ejemplos que constituyen modelos de cognición para la sociedad española en general, como la transformación que sufrieron muchos de los llamados santos, y quizá más conocido el de la conversión de San Pablo7 . El despertar del protagonista es el despertar que se vende a cada espectador; postula la necesidad de cambiar nuestra percepción para transformar el ambiente negativo en positivo. Algunas tradiciones espirituales describen la vida de la mayoría de las personas, antes de tomar decisiones transformadoras, como muerte, como si las personas actuaran de forma automática, reactiva, bajo patrones y hábitos sin llegar a saber quiénes son realmente. Esta idea es la esencia del mensaje del spot: necesitamos abrir los ojos a otra realidad, también presente, a la que no prestamos la atención suficiente y es la que (de verdad) importa. Campofrío está ofertando una transformación pero no en términos políticos ni sociales, sino de ánimo personal;

6 La serie que RTVE emitió en prime time entre 2010-13 y tuvo un alto índice de audiencia, que se mantuvo en alrededor de los cuatro millones de espectadores, además de mantener, hasta hoy en día, en su web la serie completa, por lo que ha podido ser visionada por muchas más personas.

7 Considerado en la tradición cultural católica española como el que mejor representa el tema de la conversión, que ha sido muy representada en el arte por los más famosos pintores, ya en la Edad Media, pero sobre todo a partir del siglo XVI. 
un renacer terapéutico e iluminador donde la crisis es la oportunidad, el punto de inflexión hacia una vida mejor.

\subsection{Desarrollo argumental del drama: volver a empezar, la terapia}

El desarrollo argumental muestra la vuelta del protagonista a su vida, una vida e identidad que no recuerda, y a través de la mediación de su esposa (Emma Suárez), acompañamos al hombre en su volver. El protagonista recorre la historia de su vida aplicando así una de las estrategias publicitarias más frecuentes y exitosas del llamado branding emocional: el uso de la narrativa o storytelling. La historia de vida es una de las estrategias publicitarias que ayudan a conectar a las marcas con su audiencia. Las marcas usan narrativas que demuestran un conocimiento genuino y comprensión de los estilos de vida, sueños, objetivos y valores de los consumidores, y muestran cómo la marca podría enriquecer sus vidas. Según Thompson, Rindfleisch and Arsel (2006) el objetivo del branding emocional es crear fuertes y significantes vínculos con sus consumidores y así llegar a formar parte de sus historias de vida, memorias e incluso identidad.

Una de las estrategias que Despertar emplea para establecer un fuerte vínculo con la audiencia es dotar a la historia que cuenta de un carácter real y auténtico. Así, a nivel temporal, el tiempo de la narración coincide con el tiempo real, a través de referencias a la navidad, el momento en que fue lanzada la campaña; y a nivel espacial situándolo de manera inconfundible en España. Los espacios tanto exteriores - calles, plazas, ciudad o campo- como interiores - la casa-, son perfectamente reconocibles, reales, y a la vez altamente simbólicos, testigos de los acontecimientos cotidianos de la vida de los españoles. La identidad y valores del protagonista que se va descubriendo, lo presentan como un hombre común y creíble, de unos 45 años, de clase media, casado, con una hija y un perro. Tiene familia, padres, hermanos y amigos, quienes socializan y comparten sus aficiones: música y fútbol. Vive en una ciudad y visita a veces su pueblo. Una persona, y una familia tradicional, al uso, que responde a la norma española con la que la audiencia puede conectar fácilmente. En cuanto a los valores y actitudes sociales que priman en el spot son los que se consideran españoles, nuestra manera de ser, según el spot, $\mathrm{y}$, sobre todo, en el tiempo de Navidad: con especial énfasis en familia, grupo, amistad, tradiciones, celebraciones, reuniones.

El proceso de reencuentro, re-conocimiento del protagonista con su vida y el mundo es, principalmente, emotivo. Las emociones conectan al protagonista con el mundo y ayudan a la audiencia a conectarse con él, sentir con él y su familia, siempre presente, y por supuesto con la marca, con la que desarrolla un sentimiento de confianza igual que el que trasmite el protagonista. Que la historia emocione es uno de los principales objetivos de la campaña. Las emociones en los textos multimodales requieren un análisis que se torna complejo, pues se expresan en los diferentes modos: oral, escrito visual, sonido, sensorial, etc., y pueden ocurrir en varios de ellos al mismo tiempo. Sin entrar a definir qué es una emoción, es nuestra intención analizar cuáles y cómo se representan. Teniendo en cuenta que el protagonista se encuentra en un estado puro o de inocencia, pues ha perdido la memoria, y con ella su identidad y la percepción del ego, las emociones y su expresión se entenderán por parte del espectador como honestas; mirar la vida como la primera vez conlleva una falta de creencias, prejuicios, que nos vamos creando a medida que convivimos en sociedad. 

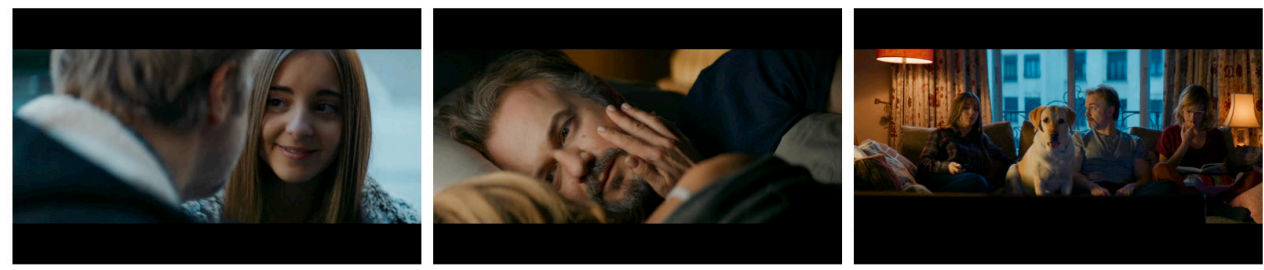

Figura 2. Planos 16, 28 y 42 del spot Despertar de Campofrío (2015)

[Fuente: spot Despertar de Campofrío (2015)]

A través de primeros planos de la cara y los ojos del protagonista se expresan sorpresa, curiosidad y alegría, que a veces parecen contenidas al ver a su hija, familia y amigos, y al maravillarse al mirar el cielo o su pueblo. Sensoriales olfativas, a través de acciones como oler el pelo de su esposa; el sentido del tacto de la mano de su hija agarrando la suya, o la mano de su mujer acariciándole la cara. Del sentido del gusto, al probar los productos de Campofrío. Pasión viendo el partido de fútbol, tocando la guitarra o disfrutando de la velocidad en la bicicleta. Ternura y amor al pasear de la mano de su hija. En las acciones grupales: reír, abrazar, besar, que demuestran alegría, camaradería, confianza, amor y bienestar. Y la que parece ser más importante, pues es la única que se nombra: el amor, representada en la mirada de su esposa. De hecho, todos los momentos que constituyen su vuelta al mundo están cargados de emoción, y todas las acciones que se representan son positivas, de alegría y bienestar. El protagonista no habla, va recogiendo, empapándose de sabiduría, desde una mirada nueva que no juzga, no trae memorias ni prejuicios que obstaculicen la percepción de la realidad. El mundo que reconoce coincide con el del espectador, y de este modo las emociones se perciben como auténticas, dado que la idea de autenticidad es una construcción social y cultural que se comparte. En este acto de comunicación se comparten dichas emociones por toda la sociedad como "nuestra forma de sentir, de disfrutar", que el eslogan reconoce.

Otra modalidad discursiva que apela a las emociones de los espectadores es la música. La banda sonora, que comienza a sonar durante la representación de la vida del protagonista, y tras las palabras del doctor "es un poco como volver a empezar", es la canción Volver en la versión flamenca de Estrella Morente, una canción y letra muy conocida por la sociedad española ya desde los años 30 en que se creó como tango. La versión de Morente, se hizo famosa a partir de la película de Almodóvar Volver (2006) que recibió, entre otros premios, cinco Goyas en 2007. La letra hace referencia también a las emociones y el sentimiento efímero de la vida: volver, recordar, llorar, sentir.

En la narración de esta historia de vida se echan de menos algunos aspectos, singularmente aquellos que no coinciden con parte del eslogan del spot: disfrutar de la vida. Así, no sabemos cuál es la profesión del protagonista, ni se muestra ningún espacio en el que tenga lugar lo que consideramos habitualmente como trabajo (aunque en el caso del hospital y el bar haya trabajadores). No se menciona tampoco el evento o la causa de la crisis personal y de salud, ni se representa la crisis económica en ningún momento de este desarrollo. 


\subsection{Desenlace. EI mensaje, la crisis como oportunidad}

La crisis como trauma frente a la crisis como oportunidad para cambiar, crecer e incluso iluminarse. El desenlace de la historia sobreviene durante una reunión festiva con amigos en la plaza del pueblo, alrededor de una mesa en la que se sirven los frutos de la marca Campofrío y es aquí donde la crisis económico-social-política que está sufriendo España se hace presente a través de la reacción emocional, de rabia y estrés (¿quizás envidia?) que uno de los amigos tiene tras leer el periódico. Es decir, se presenta a través de las secuelas psicológicas que la crisis, o la representación de esta en la prensa, produce. El hombre expresa de manera enfática un deseo de "meterse en la cama, cerrar los ojos y no volver a abrirlos", producido por la desesperanza y depresión que la crisis le ha generado. Este amigo toma el rol de traidor o aguafiestas de la celebración que están disfrutando y su postura es la opuesta de la nueva mirada que el protagonista adquiere.
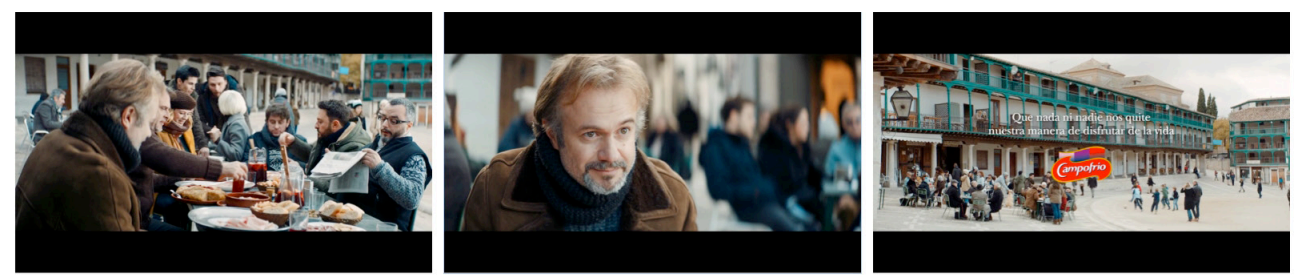

Figura 3. Planos 60, 68 y 77

[Fuente: spot Despertar de Campofrío (2015)]

Aunque no existe en el spot un antagonista explícito como tal, sí podemos identificar dos figuras que toman ese rol. En primer lugar el antagonista es el propio yo, pero ese yo que no ha abierto los ojos a lo bello de la vida. Podríamos expresarlo como ese yo que no ha nacido de nuevo (véanse las palabras de la música y del doctor: "volver a empezar todo") o que todavía no ha descubierto otra forma de entender la vida. Este primer antagonista se muestra en el pasado del propio protagonista, el que entra en crisis. Un segundo antagonista, queda reflejado en el amigo que lee el periódico y genera malestar en el grupo al señalar todos los males por los que está pasando el país. Esto ocurre en el momento más positivo del spot, sin embargo su comentario cambia el ambiente y el entorno se vuelve hostil, pasando de la alegría al pesimismo, por lo que es abucheado por sus amigos. En su caso, todavía no ha purificado su manera de disfrutar la vida y queda retratado en el spot como el antónimo de lo que se pretende transmitir.

El recurso estilístico del paralelismo que el spot establece entre las dos crisis, la de la historia del protagonista, una crisis de salud física (el trauma encefálico-craneal y el consecuente coma y pérdida de memoria), y la crisis social, permite presentar esta última como una crisis individual, una crisis mental (la depresión y pérdida de ganas de vivir) que está sufriendo el amigo.

El paralelismo permite también ofrecer la visión de que ante una crisis, ya sea social o individual, uno puede deprimirse y sufrir, o aprovecharla como una oportunidad que la vida nos presenta para cambiar y crecer. Es decir, que la solución que propone es siempre individual. La teoría de que las personas pueden cambiar a mejor de 
forma significativa tras pasar por experiencias difíciles, y de gran sufrimiento, ya sea enfermedades, desastres naturales, guerras, grandes cambios sociales, pérdidas de seres queridos o materiales, no es nueva, y podemos encontrarlas en la literatura griega clásica, así como en las diferentes tradiciones de la mayor parte de las religiones, cristiana, hebrea, musulmana, budista, hinduista, y en las llamadas nuevas espiritualidades, especialmente de influencia oriental. Sin embargo, la investigación científica de este fenómeno se intensifica a partir de la segunda mitad de los años 90. Calhoun y Tedeschi (2013) definen el crecimiento postraumático (posttraumatic growth) como la experiencia de cambio positivo que un individuo experimenta como resultado de la lucha contra un acontecimiento traumático. El éxito de esta teoría y las investigaciones al respecto tiene su origen, en parte, en el movimiento conocido como psicología positiva. El estudio del crecimiento postraumático, es decir, la crisis como oportunidad, se encuentra muy extendido hoy en día y ha influido en otras disciplinas fuera de la psicología, por ejemplo los estudios de management y administración de empresas.

Los investigadores Calhoun y Tedeschi (2013) organizan el método analítico sobre la terapia de crecimiento postraumático en tres categorías generales: cambio en la percepción de uno mismo, cambio en la percepción de las relaciones con otras personas, y cambio en la filosofía de vida personal. Durante el desarrollo de la trama de la historia de vida que contiene el spot, se pueden encontrar claramente representadas las tres categorías. La primera categoría se encuentra en la propuesta narrativa. Ya desde las primeras imágenes, el protagonista es un hombre nuevo al despertar del coma, sin memoria, y por lo tanto la nueva personalidad se creará a partir de ese evento. Una actitud diferente ante las relaciones, familiares o de amistad, y lo que Calhoun y Tedeschi expresan como "descubrir quiénes son tus verdaderos amigos" (2013: 8) es literal en el caso de spot, pues de ese redescubrimiento (junto con el de la familia y la sociedad en la que vive) se ocupa la mayor parte de la historia narrada. El tercer aspecto, el de un cambio de filosofía de vida y una mayor apreciación de ésta, se va viendo a lo largo del spot a través de las emociones que se representan, todas positivas, como remarcamos. Se prioriza lo positivo y disfrutable de la vida y se deja fuera lo que pueda molestar o crear emociones negativas. Según los autores, en este tercer punto algunas personas lo experimentan como una mayor percepción o compresión espiritual o religiosa.

El paralelismo o comparación entre la situación de los dos amigos también le permite al protagonista demostrar el crecimiento que ha tenido lugar en él tras el trauma sufrido. En esta última escena, el protagonista habla por primera vez, mostrando su sabiduría, la del que ha estado más allá y ha vuelto, ha superado la prueba, y que ofrece como una enseñanza al responder al amigo: "Pero créeme que hay demasiadas cosas cada día por las que merece la pena abrir los ojos, levantarse y salir a vivir", dice, a la vez que va mirando eso que merece la pena para él: su mujer, su hija y el perro y todos los amigos con él sentados a la mesa: "Esto es la vida". El modelo cognitivo de referencia para la audiencia española de esta situación es la última cena en la que el maestro se reunió con sus discípulos para comer y beber y mostrarse como ejemplo de vida; un tema que ha sido abundantemente representado por las artes plásticas y gran referente de la cultura occidental. Una referencia, que al ser sacada del contexto religioso y mostrada como una terapia, se seculariza ofreciéndose como un renacimiento a la vida, como una iluminación, $\mathrm{y}$, por lo tanto, como una solución definitiva. 
La resolución de la trama viene de la mano de una definición metafórica de la crisis: como una buena siesta española, una oportunidad para descansar y volver renovado, como entre risas y ambiente distendido tras la enseñanza del protagonista, dice la voz de uno de los amigos a la vez que el spot se va cerrando. Esta definición de crisis le quita importancia a las otras definiciones, tanto a la personal como a la social, y ofrece una solución individual y al alcance de todos, además de ser la más española, reivindicando una vez más nuestra manera de disfrutar de la vida.

\subsection{El discurso del Despertar espiritual}

El spot narra una historia de superación (de la superación de una crisis), la salida del coma y la recuperación de la memoria de un hombre. Sin embargo el tema en el que se engloba es más amplio: un despertar espiritual. Desde las referencias a transformaciones religiosas, o a historias de vida de personajes fundamentales de la religión cristiana, si bien en situaciones sociales cotidianas y no religiosas en el spot, hasta imágenes y expresiones, el anuncio nos va introduciendo en un discurso de esencia espiritual. Así, el consejo del protagonista con que el spot concluye comienza con el imperativo, usado como apelativo y con intención de consejo y persuasión: "créeme", y que refiere a la audiencia en términos de confianza y fe. Así mismo la aseveración "esto es la vida", enfatiza la última palabra proveyéndola de un significado que supera al habitual, que va más allá de lo cotidiano y lo mundano, para transcenderlo. La cámara enfoca al protagonista y a esas cosas que son "la vida", mostrándole como una persona sincera que mira a los ojos del amigo, tranquila, comprensiva e incluso compasivamente, contrastándolo con la actitud del amigo que muestra desesperación e irritabilidad.

La situación y las palabras del protagonista al final del spot le dan un significado a las imágenes previas, las de su vuelta a vida, que va más allá de la expresión de unas emociones de alegría y bienestar, para dotarlas de esa idea de vida transcendida y espiritual. Sus expresiones, su forma de mirar maravillada y actitud reflexiva, denotan entonces una especial atención al momento presente, a la naturaleza y a las personas con las que se encuentra, desde un estado de presencia total, o lo que se denomina mindfulness: una observación sin crítica y compasiva, como una forma de meditación continua.

Volviendo a la definición de contexto de Van Dijk (2008) como constructo cognitivo en el que se actualizan y reconocen conocimientos y experiencias, o modelos cognitivos compartidos, y que otorga sentido al mensaje, este discurso que denominamos espiritual no estaría fuera de contexto en la sociedad actual. De hecho, el filósofo social Christopher Lasch (1991) ya definía este clima espiritual terapéutico como una forma de vida en la que el individuo desarrolla una exacerbada preocupación por sí mismo. Rieff (1987) lo llama "hombre psicológico" en su obra sobre el triunfo de lo terapéutico, y David Brooks (2002) se refiere a ello como "egoísmo refinado" cuyo imperativo es la auto-cultivación. La búsqueda política de la década de los sesenta en Estados Unidos - contracultura, protesta y oposición al establishment - dio paso a una búsqueda personal por la autorrealización y la construcción individual: la sociedad se convenció de que debía buscar elementos positivos para "su reconstrucción espiritual en la sabiduría oriental y los ejercicios de relajación; el objetivo fue perder el miedo al placer que siglos de cultura puritana 
habían convertido en sinónimo de pecado y decadencia moral" (Girola, 2005: 243). En palabras del propio Lasch:

\footnotetext{
Las personas de hoy no ansían la salvación personal, ni restaurar una edad de oro original, sino los sentimientos, la ilusión momentánea, el bienestar personal, la salud y seguridad psíquica [...]. Vivir el presente es la pasión dominante: vivir para uno mismo, y no para tus predecesores o tus descendientes (1991: 30 y 33).
}

De esta forma, Lasch identifica el clima espiritual contemporáneo no como religioso sino como terapéutico. En la misma línea, Rifkin afirma que "la vida es muy corta para sacrificarse por la historia y por un paraíso futuro, más aun si la autorrealización y el bienestar ya están al alcance de la mano" (2000: 266). También Hoover (2006: 52) argumenta que el perfeccionamiento del self se ha convertido en el proyecto social central de nuestro tiempo en la llamada cultura de la terapia, basada y disponible a través de los media y la cultura consumista. Según Lipovetsky el consumidor actual "quiere recuperar la dimensión del ser o la espiritualidad" (2007: 39), es un consumidor que ha recuperado su dimensión transcendente o, más bien, que cuando los grandes sistemas referenciales han caído, lo busca en otros, encontrando en la sociedad de consumo dicha profundidad. Y en una entrevista de Rifkin (2000: 243) a Jane Rinzler Buckingham, presidenta de la Youth Intelligence, informa que la espiritualidad será lo que dé el golpe entre la generación del clubbing a ambos lados del Atlántico, y afirma: "que Madonna se ponga un tercer ojo hindú en la frente no es demasiado importante, pero esa moda indica que la gente está buscando más espiritualidad en sus vidas". Rifkin señala que las empresas, sabedoras de que la cultura juvenil ansía espiritualidad, incorporarán símbolos, temas e imágenes espirituales en sus campañas de marketing y publicidad para demostrar a sus potenciales clientes que entienden su lenguaje (2000: 243).

En sus investigaciones sobre publicidad, Marmor-Lavie, Stout, \& Lee (2009) construyen un marco para el análisis de la espiritualidad en la publicidad (SAF: Spirituality in Advertising Framework). Proponen una práctica interdisciplinaria y holística para estudiar la espiritualidad en la investigación publicitaria en la que identifican dieciséis características o aspectos que contribuyen a transmitir la idea de espiritualidad en los mensajes publicitarios, y que ya ha sido utilizada en varios estudios publicados (Janicke y Ramasubramanian, 2017; Marmor-Lavie y Stout, 2016). La mayor parte de estas características se cumplen en el spot Despertar y han sido descritas previamente, aunque ahora solo repasaremos algunas. Por ejemplo, lo que los autores denominan el componente de la acción, se encuentra en el spot ya desde el título, ese despertar a la vida consciente, volver a la vida renovado, con una visión transformada. La idea de que la búsqueda y el logro suponen más que una gratificación instantánea, y que en el spot se muestra como un cambio profundo del entendimiento de la vida, de la forma de vivir y que una vez adoptado servirá para siempre. Otra de las propuestas es la presencia de la idea de soltar, o dejar ir, con el significado de dejar marchar las viejas creencias y percepciones y abrirse a la vida, que es en suma el consejo del protagonista en Despertar ante el empeño del amigo de quedarse anclado en la desesperanza y la queja por la situación de crisis social, lo que le llevaría a saber apreciar lo que tiene, en una actitud de gratitud que mencionan también los autores de SAF, y que sí podemos ver en el protagonista. Vivir el presente dará como resultado una mayor consciencia de la 
vida, o mindfulness, que, como hemos visto, son unas constantes en el anuncio, a través de la vuelta a la vida y la recuperación de la memoria que constituyen la parte central del anuncio, y expresa en su mensaje: "hay demasiadas cosas cada día por las que levantarse y vivir". Sufrimiento y transformación es el argumento del anuncio como crisis y superación de ella. Otra de las características que Marmor-Lavie et al (2009) proponen es la acción de asumir la responsabilidad, es decir asumir que somos responsables de nuestra propia vida, de lo que pensamos, sentimos y cómo vivimos, porque como expresa el protagonista de Despertar, en vez de creer que nuestra vida depende de causas ajenas a uno mismo, como en el caso del amigo que se queja de la crisis social, el protagonista asegura que siempre habrá situaciones que no nos gusten; después de todo, "la vida no ha cambiado tanto" y la responsabilidad de cómo vivir es de cada uno.

Relacionada con el tratamiento de la psicoterapia, la propuesta del spot reúne características de una "religiosidad más terapéutica" (Mardones, 1996: 129), de la "búsqueda de la paz interior", la "salud emocional", la "higiene mental", la "armonía interna" (Griera i Llonch y Urgell Plaza, 2002: 94) o de una "industria trascendente" (Gil Soldevilla et al., 2014). La realización personal está en su centro, vehiculando problemas y angustias de la vida cotidiana mediante el autoconocimiento, la gnosis interior, la mejora a sí mismo, porque será ese yo íntimo quien otorga la salvación sea cual sea el contexto que estamos experimentando.

Esto conecta con una máxima del sistema neoliberal: usted es el único responsable de lo que le pase. Eagelton-Pierce (2016) hace referencia a tres temas principales que se encuentran en el espíritu de la ideología neoliberal, y que acompañarían esquemas de justificación y patrones de pensamiento que se encuentran en experiencias de vida. El primero es el individualismo, según el cual el individuo tiene prioridad sobre la colectividad. El segundo es universalismo, en las tendencias expansionistas del mercado global; y el tercero, meliorismo, según el cual los humanos tienen la capacidad de mejorar por sí mismos, lo que mejorará la sociedad. Estos tres temas se encuentran en el discurso del spot de Campofrío, por lo que podemos concluir que, en última instancia, el discurso del spot ayuda a mantener, naturalizar y legitimar la ideología neoliberal presente en el contexto en que el acto de comunicación tiene lugar.

\section{Conclusión}

El spot Despertar pertenece al tipo de publicidad denominado branding emocional que busca la conexión afectiva con las audiencias para publicitar no tanto el producto, sino la marca. Una de las estrategias del anuncio para conectar con su público es hacer que la historia que cuenta parezca real, posible o auténtica, y de esta manera hacer que tanto la historia relatada como la marca pase a formar parte de la vida, recuerdos y emociones de la audiencia. Estas estrategias consiguen ganancias con sus productos, pero también influir con sus mensajes en las creencias y en las actitudes e ideologías de la sociedad que consume esta publicidad, es decir, construyen una representación de la realidad.

La crisis social no se representa de forma directa, sino a través de una comparación o paralelismo con la crisis de salud que ha sufrido el protagonista, y se muestra como una crisis más, como una dificultad por la que cualquier individuo puede pasar en 
esta vida. Por una parte esta representación resta importancia a la crisis, al dessocializarla y des-politizarla, a la vez que la individualiza, así como sus posibles causas, consecuencias y soluciones, apoyando y legitimando la ideología neoliberal presente en la sociedad.

El spot propone en la historia que narra la posibilidad de usar la crisis como oportunidad para despertar a otra realidad posible y, a través del vínculo que crea con la audiencia, esta posibilidad acompaña al protagonista en la experiencia terapéuticoespiritual, ofreciéndose así la marca como terapeuta, coach personal e incluso gurú espiritual para superar las crisis. La publicidad tiene la intención de suturar la quiebra de la realidad cotidiana, pero dicha sutura solo es estética y efímera. En definitiva, ésta rechaza cualquier intento de transformación del mundo a través de la política o la activación social, opta por una huida hacia el misticismo del mundo interior, del autoconocimiento, de la experimentación de las pequeñas cosas.

\section{Bibliografía}

Bauman, Z. (2007). Vida de consumo. Madrid: Fondo de Cultura Económica.

Bauman, Z. (2010). Mundo-consumo: ética del individuo. Barcelona: Paidós.

Brooks, D. (2002). Bobos en el paraíso. Barcelona: Debolsillo.

Calhoun, L.G. y Tedeschi, R.G. (2013). Posttraumatic Growth in Clinical Practice. New York: Routledge.

Campofrío Food Group (s.f.) Campofrío (2017). Recuperado de http://www.campofrio.es/ campofrio.html (Fecha de acceso: 20/07 2017).

Castelló, A., Ramos, I. y Del Pino, C. (2013). "El discurso publicitario en la crisis económica: nuevos valores y redes sociales". Historia y Comunicación Social, 18, 657-672.

De Beaugrande, R. y Dessler, W. (1981). Introduction to Textlinguistics. Londres: Longman.

Eagleton-Pierce, M. (2016). "Historicising the Neoliberal Spirit of Capitalism", en Springer, S., Birch, K., y MacLeavy, J. (eds.), The Handbook of Neoliberalism, London: Routledge, 17-26.

Fernández, E., Alameda, D. y Martín, I. (2011). "Las estrategias publicitarias de las marcas en el contexto de crisis". adComunica. Revista Cientifica de Estrategias, Tendencias e Innovación en Comunicación 1, 119-138.

Garrido Lora, M., Rey, J. y Ramos-Serrano, M. (2012) El eslogan publicitario en la encrucijada de la crisis económica. Comunicació i risc: III Congrés Internacional AE$I C$, Barcelona: Universitat Rovira i Virgili.

Gil Soldevilla, S., Palao Errando, J.A. y Marzal Felici, J.J. (2014). "Brands as New Forms of Religiosity: the Case of the World of Red Bull”. Trípodos, 35, 57-74.

Girola, L. (2005). Anomia e individualismo: del diagnóstico de la modernidad de Durkheim al pensamiento contemporáneo. México, D.F. : Universidad Autónoma Metropolitana.

Gottschalk, S. (2009). "Hypermodern Consumption and Megalomania: Superlatives in commercials". Journal of Consumer Culture, 9(3), 307-327.

Griera i Llonch, M. del M. y Urgell Plaza, F. (2002). Consumiendo religión: un análisis del consumo de productos con connotaciones espirituales entre la población juvenil. Barcelona: Fundación La Caixa.

Hoover, S.M. (2006). Religion in the Media Age. New York: Routledge.

Janicke, S.H. y Ramasubramanian, S. (2017). "Spiritual Media Experiences, Trait Transcendence, and Enjoyment of Popular Films". Journal of Media and Religion 16(2). 
Kress, G. y Van Leeuwen, T. (2001). Multimodal discourse. The modes and media of contemporary communication. Londres: Arnold.

Lasch, C. (1991). The Culture of narcissism: american life in an age of diminishing expectations. London: W. W. Norton.

Lipovetsky, G. (2007). La felicidad paradójica. Barcelona: Anagrama.

Mardones, J.M. (1996). ¿Adónde va la religión?: cristianismo y religiosidad en nuestro tiempo. Santander: Sal Terrae.

Marmor-Lavie, G. y Stout, P.A. (2016). “'Consumers' Insights About Spirituality in Advertising”. Journal of Media and Religion 15(4), 169-185.

Marmor-Lavie, G., Stout, P. y Lee, W.N. (2009). "Spirituality in Advertising: A New Theoretical Approach". Journal of Media and Religion 8(1), 1-23.

Planelles, C. (2009). "La crisis económica se adueña de la publicidad". El Mundo. Recuperado de http://www.elmundo.es/elmundo/2009/03/22/comunicacion/1237723012.html (Fecha de acceso: 17/07/2017).

Rieff, P. (1987). The Triumph of the Therapeutic: Uses of Faith After Freud. Chicago: University of Chicago Press.

Rifkin, J. (2000). La Era del acceso: la revolución de la nueva economía. Barcelona: Paidós.

Rodríguez Serrano, A., Gil Soldevilla, S. y Marzal Felici, J. (2015). "Las crisis del Habitar: Cine y publicidad en el Branded Content Cinergía - Gas Natural Fenosa ". Questiones Publicitarias I(20), 142-159.

Thompson, C.J., Rindfleisch, A. y Arsel, Z. (2006). "Emotional Branding and the Strategic Value of the Doppelganger Brand Image". Journal of Marketing 70, 50-64.

Van Dijk, T.A. (1999). Ideología. Una aproximación multidisciplinaria. Barcelona: Gedisa.

Van Dijk T.A. (2008). Discourse and Context. A Sociocognitive Aproach. Cambridge: Cambridge University Press. 